\title{
Energy Valuation Methods for Biofuels in South Florida: Introduction to Life Cycle Assessment and Emergy Approaches $^{1}$
}

\author{
J. Van Treese II, E. A. Hanlon, N. Y. Amponsah, J. L. Izursa, and J. C. Capece²
}

\section{Introduction}

Recent changes in the United States requiring the use of ethanol in gasoline for most vehicular transportation have created discussion about important issues. For example, hybrid corn is the dominant way that plant energy has been converted to ethanol. This alternative use for corn consequently changed the amount used for food products (Figure 1) (Brown 2012a and 2012b).

Shifting the use of corn from food production to energy supply has created considerable debate about the biofuels industry. The industry is no stranger to controversial issues, as there has also been discussion about federal subsidies, tradeoffs between food production and energy production, and speculation about biofuels as a possible means for energy security. The idea that a nation, state, or county can grow fuel is intriguing and an invitation for invention. One plant-to-fuel concept after another has been brought forward. Many are inventive, and others require research to make the idea practical and sustainable.

One reason biofuels and biofuel processes have been debated so much is that with the appropriate process, biofuels might be able to provide a substitute for traditional fossil fuels while producing fewer greenhouse gas (GHG)
U.S. Corn Use for Feedgrain, Fuel Ethanol, and Exports, 1980-2011

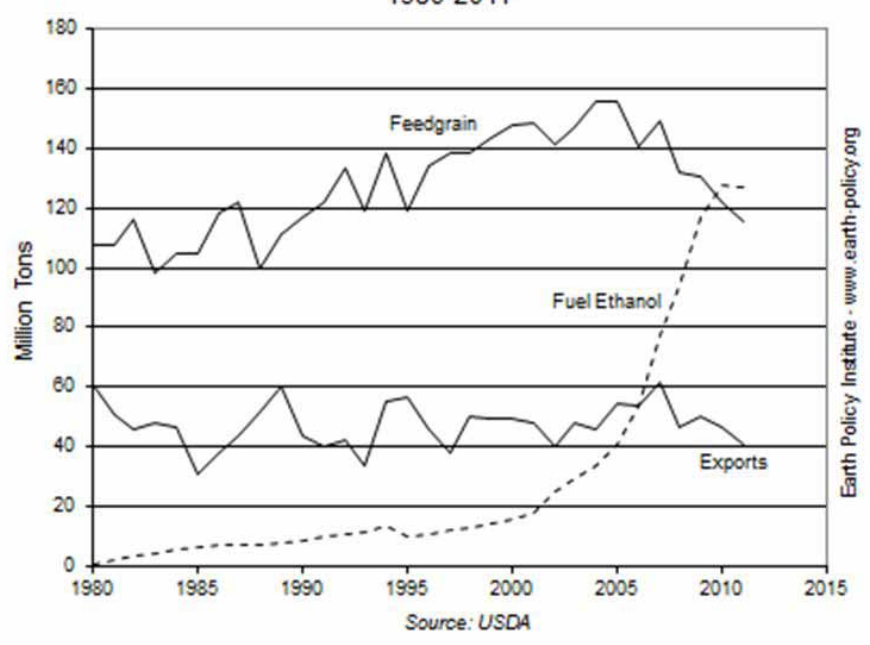

Figure 1. Corn use in the United States from 1980 to 2011. Credits: Earth Policy Institute

emissions. A second and equally important reason is that biofuels address energy security for the country. At the same time, biofuel processes (i.e., farming) can also affect other resources such as the atmosphere and water. Also, biofuels must be produced in a way that a usable energy source is obtained without generating by-products (wastes) that require additional treatment or disposal.

1. This document is SL377, one of a series of the Department of Soil and Water Science, Florida Cooperative Extension Service, Institute of Food and Agricultural Sciences, University of Florida. Original publication date March 2013. Visit the EDIS website at http://edis.ifas.ufl.edu.

2. J. Van Treese II, PhD student, Department of Soil and Water Science; E. A. Hanlon, professor, Department of Soil and Water Science, Southwest Florida Research and Education Center, Immokalee, FL; N. Y. Amponsah, research associate, Department of Soil and Water Science; J. L. Izursa, research associate, Department of Soil and Water Science; and J. C. Capece, president, Intelligentsia International; Florida Cooperative Extension Service, Institute of Food and Agricultural Sciences, University of Florida, Gainesville, FL 32611. 
Because sustainability is often discussed as a component of biofuel production, research methods must accurately assess the extent to which a given practice is sustainable. A sustainable approach requires understanding inputs (i.e., energy required to carry out a process, both natural and anthropogenic) and outputs (i.e., energy produced by that process). This approach should include the entire process, as well as environmental considerations that can be overlooked in a more traditional approach.

Considering the environmental aspects of biofuel production allows an evaluation that can lead to a more sustainable process. Many economic analyses only address those components that have definitive economic value to the industry or process and may leave out components with a value that is overlooked or not readily available (i.e., the costs associated with air pollution or water pollution). These components may be called "externalities," but in effect consideration of only selected parts of the entire process limits the evaluation's scope to those that are specific to the company or the industrial sector. To this end, two methods have emerged as promising means of assessing sustainability: (1) Life Cycle Assessment (LCA) and (2) Emergy Assessment (EA).

This publication gives an overview of these methods for evaluating energy transformations in biofuels production. The LCA approach involves measurements affecting greenhouse gases (GHG), which can be linked to the energy considerations used in the EA. Although these two methods have their basis in energy or GHG evaluations, their approaches can lead to a reliable judgment regarding a biofuel process. Using these two methods can ensure that the energy components are well understood and can help to evaluate the economic environmental component of a biofuel process. In turn, using these two evaluative tools will allow for decisions about biofuel processes that favor sustainability. The intended audiences of this publication are growers, researchers, students, and any other readers interested in agriculture and ecology.

\section{Life Cycle Assessment}

LCA is an evaluation method that follows a production, utilization, and ultimate disposal evaluation of energy transformations, often referred to as the "cradle-to-grave" approach. The International Organization for Standardization (ISO) defines LCA as the "compilation and evaluation of the inputs, outputs, and potential environmental impacts of a product system throughout its life cycle" (ISO 2006, pg. 2). LCA measures sustainability by evaluating the cumulative ecological impact of the production process, including resource consumption and pollution as a function of the equivalents of carbon dioxide produced $\left(\mathrm{kg} \mathrm{CO}_{2} \mathrm{e} \mathrm{kg}^{-1}\right)$. The basis for using the GHG carbon dioxide is to have a common unit of measure.

For instance, an LCA of an automobile is comprised of all the parts necessary to make the car work, such as the battery for the vehicle to start and run, as well as the labor and materials to build and maintain the car. In addition, an automobile's LCA includes the environmental impact caused by the vehicle's manufacturing and use. All of these manufacturing and carbon conversions can be expressed as the equivalent effects of carbon dioxide. An LCA assessment helps determine a product's sustainability because every aspect of the production, use, and disposal can be analyzed for the effects the product has on the environment. Another example is the use of sugarcane as a biofuel feedstock (Izursa 2013).

\section{Life Cycle Inventory}

Life Cycle Inventory (LCI) is the start of an LCA evaluation. The LCI includes a list of input and output energy flows as carbon dioxide equivalents and does not include any consideration of environmental effects. A list of materials and energy defines the inputs to the process. A second list of products, by-products, emissions to the environment, and waste describes the outputs of the process.

\section{Life Cycle Impact Assessment}

Life Cycle Impact Assessment (LCIA) is usually based on either a unit of production or the total expected production from the process. For example, biofuel production might be based on growing the biofuel feedstock on one acre of land or on the total acres expected to produce the feedstock. There are four primary impact assessment metrics; the lower the value of each metric, the more sustainable the process:

1. Global warming potential (GWP) is the most cited impact assessment metric. GWP reflects the amount of warming that can be predicted based on the carbon dioxide equivalent values used in the LCIA. The GWP is usually expressed as the weight of the by-product emissions converted to carbon dioxide equivalents. For example, harvesting and hauling biomass feedstock are typically associated with a large GWP due to the fuel and machinery involved.

2. Acidification potential (AP) is the amount of atmospheric pollutants that can contribute to acid rain. As with GWP, the AP is reported as an equivalent unit, 
in this case the weight of equivalent moles of $\mathrm{H}^{+}$. The lower the AP, the fewer acidic emissions are generated by the process. For example, fuel use for field operations to implement cultural practices dominates the AP for sugarcane biofuels (Baucum and Rice 2009).

3. Eutrophication potential (EP) is the amount of pollutants in water and/or waste by-products expressed as the weight of nitrogen equivalents. This process is similar to converting greenhouse gases to carbon dioxide equivalents. Nitrogen is the standard for EP because this element plays a central role in the eutrophication of water bodies. As with AP, the goal should be to have a low EP value, meaning that the process avoids contributing nitrogen or equivalent compounds to adjacent water bodies. Cultural practices in biomass production (e.g., fertilization management) might contribute to increased EP values.

4. Primary energy demand (PED) spotlights the energy use (often fossil fuels) involved in the process. In the case of biomass production, PED would be expended during cultural practices (e.g., tilling, using fertilizers, etc.) and harvesting (removing the biomass from the field and transporting the material to the ethanol or cellulosic plant).

Calculating these LCA components allows for the interpretation and evaluation of a selected process. Once completed, other processes may be compared with the initial biofuels process. More importantly, using the LCA and its related tools helps to explore changes to the current system to lower environmental effects, reduce costs of production through cultural and harvesting advancement, or confirm the validity and sustainability of the existing process.

\section{Emergy Analysis}

Emergy, or embodied energy analysis, seeks to evaluate the available solar energy used directly and indirectly to provide a service or product (Odum 1995). The unit used to measure emergy is the solar emjoule, which is the energy consumed in transformations to create the service or product.

This evaluation method examines the ecosystem services and human inputs that drive a process and that are subsequently embodied within the resulting product or service. Ecosystem services represent natural contributions like sunlight, rainwater, groundwater, microbial processes, photosynthesis, and other natural resources that drive a production process. In other words, emergy evaluates a product as a series of energy transformations from one source to another until the finished product emerges.

To use the automobile example, emergy analysis would include all of the ecosystem services necessary to produce a car, including natural reserves of iron ore and other minerals, as well as the water, microbes, and sunlight required to grow cotton for the interior upholstery.

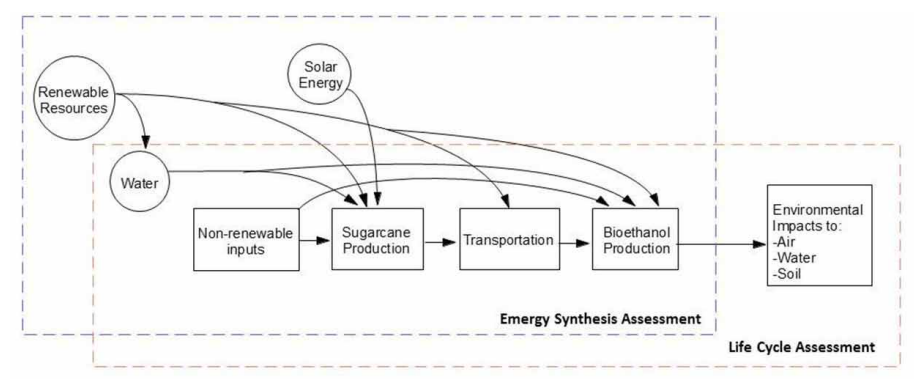

Figure 2. Scale and scope comparing and contrasting LCA and EA. In this case study, the author was working with sugarcane biofuel. Credits: Adapted from Rajvanshi 2010.

The distinction between LCA and EA (Figure 2) is that LCA focuses on inputs and outputs used in production, use, and disposal, while EA examines ecosystem services not captured by a traditional cost analysis. LCA yields a matrix quantifying the various inputs and outputs, each reported in their respective units (e.g., water, fuel, soil, etc.), whereas EA reports sunlight, fuel, electricity, and human services, reduced to a common unit (emjoules). Thus, EA measures and compares different systems using a common energy currency.

A major advantage of EA is that it is multidimensional. In other words, EA presents a metric that consists of environmental, social, and economic components, which help to determine the sustainability of a process. These components can be influenced to a greater or lesser extent by some process change, such as an improvement in efficiency or new technology.

\section{Transformity}

Transformity, or the emergy invested per unit process output of available energy, is a useful measure of sustainability. A lower transformity value means a more efficient system, indicating a reduced need for solar energy equivalents per unit of production.

\section{Energy Yield Ratio}

Energy Yield Ratio (EYR) is the total emergy of a system's output divided by emergy associated with purchased materials, inputs, and services - a more traditional economic approach to defining efficiency. EYR is primarily 
a method to assess the system's ability to use local resources. A low EYR value translates to higher energy inputs to make the final product. In other words, the energy in the inputs is equivalent to most of the energy in the final product.

\section{Environmental Load Ratio}

Environmental Load Ratio (ELR) is the ratio of purchased inputs and non-renewable resources to renewable resources. A high ELR can illustrate relatively high technological inputs and/or high consumption of nonrenewable resources (Bastianoni and Marchetinni 1996).

\section{Economic Sustainability Index}

Economic Sustainability Index (ESI) measures the input to the economy per unit of environmental load (ratio of EYR to ELR). ESI measures the extent to which the economy generates output per unit of environmental degradation society incurs.

Ultimately, these emergy ratios serve as metrics to capture the environmental, social, and economic components associated with the process being evaluated. As with LCA, these calculations can be used to indicate where possible improvements to the existing process might be made. If these improvements are useful, then the process is likely more sustainable as a result.

A significant limitation of the emergy approach is that results can be misinterpreted because all relevant components are considered to be used only once in that process. For example, the system being analyzed may produce an output. That output may be considered as a by-product if no other use for that output can be identified (in other words, the output is considered a waste product in the process). However, that same output might be used in another system as a co-product. This approach means that the output is useful to the second system and the energy in that output is transformed again.

Some resources can be used in subsequent production processes and are not destroyed after being used once. For instance, storage facilities can be used many times within a given system. That is why it is important to understand that system boundaries define EA. The selected boundaries for EA may not consider the differences between by-products from the current study or the use of that same material as a co-product for a system not considered in the study.

\section{Energy Balance}

Energy balance is the total energy of inputs for a biofuel compared to the energy outputs in use as a biofuel. If the energy balance is positive, a biofuel is more likely to be sustainable in terms of energy compared to a negative energy balance (Amponsah, Capece, and Hanlon 2012). However, the biofuel must also be assessed for economical viability to determine long-term sustainability.

\section{Contrasting Life Cycle Assessment and Emergy Analysis}

Technically engineered sources of energy can also be evaluated using LCA and EA. For example, the LCA of a SUV would likely demonstrate far more energy inputs (both in manufacturing and operation) compared to a compact car. In addition, the emergy ratios would reflect greater transformity and environmental loading for an SUV compared to a compact car because so much more energy is consumed relative to the automobile's mileage. Likewise, LCA and EA can distinguish sustainable and unsustainable agricultural practices based on energy values.

In addition to the inputs and outputs accounted for in the LCA, EA also includes examination of solar energy transformation resulting in the energy source used by humans. This common energy currency can reflect sustainability by reducing inputs and outputs to solar energy values; it is similar to monetary currency that acts as a standard valuation mechanism for goods and services exchanged in a market economy.

The market price of a good or service reflects both the cost of production and the consumer's willingness to pay. However, the market price of a good or service may not reflect its sustainability because environmental damage is externalized to third parties, not the buyers or sellers. In other words, the environmental costs are hidden. That is why LCA and EA can assess sustainability by evaluating agriculture in a manner that accounts for all the hidden costs. Using the component parts of the LCA and EA processes establishes a common language (energy transformation) to compare different production processes and a means of assessing sustainability.

LCA and EA provide useful tools for evaluating biofuels' sustainability by revealing the impacts of agricultural practices that may not be accounted for. After all, there is no "bottom line" that can determine whether a given practice is sustainable. LCA and EA capture more information with respect to the true costs and benefits associated with agricultural practices by evaluating the entire production system. Using multiple metrics is helpful to assess the many interrelated issues associated with the sustainability of agricultural practices. Ultimately, sustainability is a 
multidimensional principle, and any analytical paradigm seeking to assess sustainability must account for economic, ecological, and sociological components. LCA and EA can provide this multifaceted insight into the sustainability of biofuel production.

\section{References and Additional Information}

Amponsah, N.Y., J.C. Capece, and E.A. Hanlon. 2012.

"Comparative Analysis of Sugarcane Ethanol in Florida and Brazil." Poster presentation at the Seventh Biennial Emergy Research Conference, Gainesville, FL, January 11-15, 2012.

Bastianoni, S., and N. Marchetinni. 1996. "Ethanol Production from Biomass: Analysis of Process Efficiency and Sustainability." Biomass and Bioenergy 11(5): 411-418.

Baucum, L.E., and R.W. Rice. 2009. An Overview of Florida Sugarcane. SS-AGR-232. Gainesville: University of Florida Institute of Food and Agricultural Sciences. http://edis.ifas. ufl.edu/sc032.

Brown, L.R. 2012a. Earth Policy Release Data Highlight (compiled from USDA data). Earth Policy Institute. http:// www.earth-policy.org/.

Brown, L.R. 2012b. Full Planet, Empty Plates: The New Geopolitics of Food Scarcity. New York, N.Y.: W.W. Norton \& Company.

International Organization for Standardization (ISO). 2006. Environmental Management - Life Cycle Assessment - Principles and Framework. pg. 2. Definition 3.2. ISO 14040:2006. Switzerland: ISO. http://www.iso.org/iso/ catalogue_detail?csnumber $=37456$.

Izursa, J. L. (2013). "Life Cycle Assessment of BiofuelSugarcane Ethanol Produced in Mineral Soils of Florida." Technical Report: Hendry County Sustainable Biofuels Center. pp. 53. http://www.imok.ufl.edu/docs/pdf/soils/ biofuels/Report\%20LCA\%20sugarcane\%20mineral\%20 soil\%2020130113.pdf.

Odum, H. T. 1995. "Self-Organization and Maximum Empower." In Maximum Power: The Ideas and Applications of Odum, H.T., edited by C.A.S. Hall. Boulder: University Press of Colorado.

Rajvanshi, N. 2010. "Evaluation of Assessment Methods for Bioethanol Production." Ph.D. Dissertation, Department of Mechanical Engineering. Gainesville: University of Florida. 